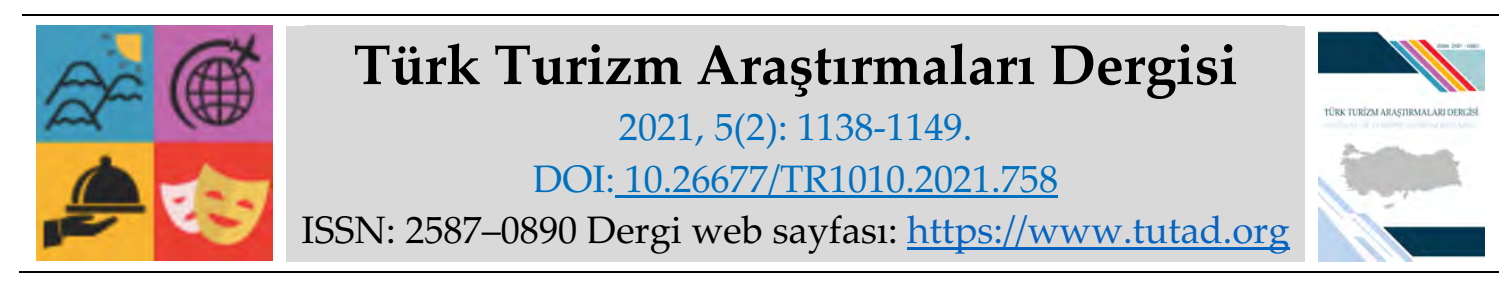

ARASTTIRMA MAKALESI

\title{
Eğitim Seviyesinin Endüstri 4. 0 Farkındalığına Etkisi: Konaklama İşletmelerinde Bir Uygulama
}

Dr. Ebru KEMER, Niğde Ömer Halisdemir Üniversitesi, Sosyal Bilimler Meslek Yüksekokulu, Niğde, e-posta: ebrukemer@ohu.edu.tr ORCID: https://orcid.org/0000-0002-7620-6297

Öz

$\mathrm{Bu}$ araştırmada, Nevşehir ilindeki konaklama işletmelerinde çalışan yöneticilerin eğitim seviyesinin endüstri 4.0 farkındalıklarına etkisini belirlemek amaçlanmıştır. Bu amaç doğrultusunda Nevşehir ilinde 2021 yılı Ocak-Şubat ayında konaklama işletmelerinde çalışan yöneticiler ile anket tekniği ile veri toplanmıştır. Araştırmada konaklama işletmeleri yöneticilerinin eğitim seviyesi ile endüstri 4.0 kavramı arasındaki ilişkiyi belirlemek için Spearman korelasyon analizi, yöneticilerin eğitim seviyelerinin endüstri 4.0 farkındalıklarına etkisini belirlemek amacıyla ise çoklu regresyon analizi yapılmıştır. Araştırma sonucunda konaklama işletmeleri yöneticilerinin eğitim seviyesindeki herhangi bir artışın, endüstri 4.0 farkındalığına yüksek kuvvette artış hissettirdiği tespit edilmiştir. Ayrıca, konaklama işletmeleri yöneticilerinin eğitim seviyesinin endüstri 4.0 farkındalığı üzerinde pozitif yönde olumlu etkilerinin olduğu sonucuna ulaşılmıştır.

Anahtar Kelimeler: Endüstri 4.0 Kavramı, Konaklama İşletmeciliği, Yöneticiler, Eğitim Seviyesi. Makale Gönderme Tarihi: 07.01.2021

Makale Kabul Tarihi: 01.06.2021

\section{Önerilen Atıf:}

Kemer, E. (2021). Eğitim Seviyesinin Endüstri 4. 0 Farkındalığına Etkisi: Konaklama İşetmelerinde Bir Uygulama, Türk Turizm Araştırmaları Dergisi, 5(2): 1138-1149.

(C) 2021 Türk Turizm Araştırmaları Dergisi. 


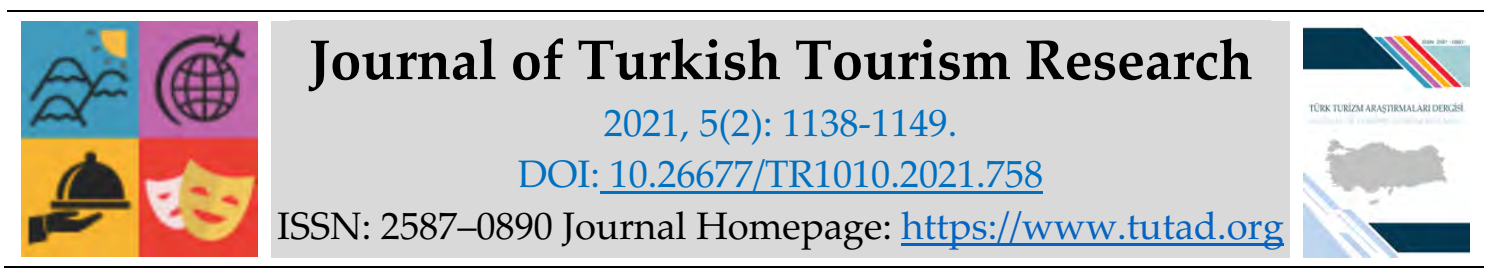

\title{
$\underline{\text { RESEARCH PAPER }}$
}

\section{The Effect of Education Level on Industry 4.0 Awareness: An Application in Hospitality Businesses}

Dr. Ebru KEMER, Niğde Ömer Halisdemir University, Social Sciences Vocational School, Niğde, e-mail: ebrukemer@ohu.edu.tr ORCID: https://orcid.org/0000-0002-7620-6297

\begin{abstract}
This study, it was aimed to determine the effect of the education level of managers working in accommodation establishments in Nevşehir province on industry 4.0 awareness. In line with this purpose, data were collected using a survey technique with managers working in accommodation establishments in the province of Nevşehir in January-February 2021. Spearman correlation analysis was conducted to determine the relationship between the education level of the hospitality managers and the concept of industry 4.0, and multiple regression analysis was used to determine the effect of managers' education level on industry 4.0 awareness. As a result of the research, it has been determined that any increase in the education level of the hospitality managers causes an increase in industry 4.0 awareness with high power. Also, it has been concluded that the education level of the hospitality business managers has a positive effect on the industry 4.0 awareness.
\end{abstract}

Keywords: Industry 4.0, Hospitality Management, Managers, Education Level.

Received: 07.01.2021

Accepted: 01.06.2021

\section{Suggested Citation:}

Kemer, E. (2021). The Effect of Education Level on Industry 4.0 Awareness: An Application in Hospitality Businesses, Journal of Turkish Tourism Research, 5(2): 1138-1149.

(C) 2021 Türk Turizm Araştırmaları Dergisi. 


\section{Gíriş}

Teknolojinin gelişmesi, dijital sistemlerin yeniliklere, farklılıklara yol açması endüstri 4.0 kavramının yeni başlangıçlar getirmesini sağlamıştır. Almanya da yeni kavram olarak ortaya çıkan endüstri 4.0 teknolojisi teknolojik altyapıların ve siber sistemlerin gelişmesini etkileyerek hayatın her alanında yenilikleri otaya çıkarmıştır (Yelkikalan vd., 2019: 32). Dengiz (2017: 40)'e göre bu yenilikler başta imalat sanayisinde olmak üzere tüm sektörlerde "enerji verimliliği" konusunda yaygınlaşmaktadır. Kısıtlı kaynaklarla kısa sürede dönüşler elde etmek sayesinde imalat sanayisinin yanı sıra Lojistik, Enerji Verimliliği, Sağlık Hizmetleri, Hizmet Sektörü vb. alanlar da Endüstri 4.0 teknolojilerinin önemli uygulama alanları haline gelmiştir. Hizmet sektörünün önemli bir parçası olan turizm sektörü de yeni teknolojilerden etkilenmiş ve bu teknolojilere hızla uyum sağlamaya başlamıştır (Dominguez vd., 2015).

Bulut ve Akçacı, (2017: 51) endüstri 4.0 teknolojilerinin cihazları akıllı hale getirdiğini, nesnelerin internet bağlantısı ile insanların ise mobil uygulamalar ile iletişime geçmeye başladığını, verilerin bulut ortamına taşındığını ve yapay zeka uygulamalarının iş dünyasında yerini almaya başladığını belirtmiştir. Turizm endüstrisinde endüstri 4.0 'a geçiş bilgisayarlı rezervasyon sistemlerine geçişle başlamış daha sonra (Sns teknolojisi ile Facebook, Twitter, Youtube gibi) sosyal medya aracılığıyla internet ile turizm hareketi devam etmiştir (Topsakal vd., 2018: 1631). Endüstri 4.0 teknolojilerinin sonucu olarak akıllı turizm uygulamalarının konaklama işletmelerinde kullanımı arttıkça konaklama işletmeleri yöneticileri bu teknolojileri kullanarak misafir memnuniyeti sağlamaya çalışmışlardır (Karamustafa ve Yılmaz, 2019: 1670). Konaklama işletmelerinin gelişen ve değişen dünya düzenine uyum sağlamaları; yenilikleri takip eden eğitimli nitelikli yöneticilerle gerçekleşebilir. Yeni teknolojilere uyum sağlayan yöneticiler bulundukları işletmelerde daha iyi hizmet sunmak müşteri memnuniyetini arttırmak için yeni yöntemler bulurlar.

Konaklama işletmeleri yöneticilerinin endüstri 4.0 farkındalıkları hem konaklama işletmelerinin müşteri memnuniyetini sağlayarak hizmet kalitesini arttırmak hem de değişen turist profiliyle eş zamanlı ilerlemek zorundadır. Bu sebeple bu araştırmanın amacı konaklama işletmeleri yöneticilerinin eğitim seviyesinin endüstri 4.0 farkındalığına etkisini belirlemektir. Araştırmanın ana problemi "Konaklama işletmeleri yöneticilerinin eğitim seviyesinin endüstri 4.0 farkındalığına etkisi var mıdır?" sorusudur. Endüstri 4.0 teknolojileri hakkında bilgi sahibi olan yöneticiler bu teknolojilerle misafirlerine daha iyi hizmet sunmak ve memnuniyet düzeylerini arttırmaya çalışmaktadırlar (Karamustafa ve Yılmaz, 2019: 1670). Misafirin memnuniyeti, misafir hakkındaki geri bildirimler hizmet kalitesinin arttırdığı için memnuniyet konaklama işletmeleri için en önemli rekabet avantajıdır. Bu sebeple, bu araştırma konaklama işletmeleri yöneticilerinin kendilerini değişen dünyaya hazırlaması, niteliklerini arttırması, yeterli eğitim seviyesine sahip değilse bu değişen düzene uyum sağlamak için farkındalıklarının belirlenmesi açısından önem arz etmektedir.

\section{KAVRAMSAL ÇERÇEVE}

\section{Endüstri 4.0 Kavramı}

Sanayi 4.0 devrimine giden tarihi süreç Endüstri 4.0 teknolojisi; birinci sanayi devrimi ilk mekanik dokuma tezgahı 1784 su ve buhar teknolojisi ile ilk mekanik üretimin ortaya çıkışı, ikinci sanayi devrimi ilk montaj hattının ortaya çıkışıla seri üretimin başlaması, üçüncü sanayi devrimi 1970 sonrası ilk programlanabilir sistemlerin ortaya çıkması, elektronik ve bilgi teknolojilerinin kullanımı ve dördüncü sanayi devrimi siber fiziksel üretim sistemleri arasında bağlantı kurma olarak ortaya çıkmıştır (Fırat ve Fırat, 2017: 11). Endüstri 4.0 kavramı ilk olarak 2011 yılında 
Hannover fuarında kullanılmıştır. Endüstri 4.0 "teknoloji temelli ve siber-fiziksel sistemlerin akıllı otomasyonu" olarak tanımlanmaktadır (Rojko, 2017: 80). Bu kavram maliyet ve verimliliği temel alan daha hızlı, verimli ve farklı pazarlama yaklaşımları ile yeni bir kavramdır (Soylu, 2017: 44). Sayısız teknolojiyi içinde bulunduran bu kavram, "Nesnelerin İnterneti (Internet of ThingsIoT), Nesnelerin Endüstriyel İnterneti (Industrial Internet of Things-IIoT), Siber-Fiziksel Sistemler (Cyber-Physical Systems- CPS), bulut tabanlı imalat (Cloud Based Manufacturing-CBM), akıllı fabrika, akıllı ürün vb.", olarak birçok kavramı içermektedir (Yang, 2017; Andreas vd., 2016; Thames ve Schaefer, 2016). Mrugalska ve Wyrwicka (2017) endüstri 4.0 kavramını, "karmaşık fiziksel makine ve cihazların, ticari ve toplumsal sonuçları daha iyi tahmin etmek, kontrol etmek ve planlamak için kullanılan ağa bağlı sensörler ve yazılımlarla entegrasyonu" veya "ürünlerin yaşam döngüsü boyunca yeni bir değer zinciri organizasyonu ve yönetimi seviyesi" olarak tanımlamaktadır.

Endüstri 4.0 kavramı rekabetçi ürünlerin ve hizmetlerin tasarımı ve uygulanması, kaynak verimliliğinin arttırılması ve pazara girme süresinin kısalması gibi zorlukların üstesinden gelebilmek için önemli bir strateji olarak görülmektedir (Rennung, 2016) Endüstri 4.0 teknolojileri ile birlikte öğrenen robotlar, büyük veri analitiği, akıllı sinyalizasyon sistemleri bilişsel teknolojiler ile yeni hizmetler sunmak mümkün olmaktadır (Özdemir Akgül, 2019: 142-143). Hizmet sektörünün bir parçası olan turizm sektöründe endüstri 4.0 kavramı verimliliğe, sürdürülebilirliğe, deneyim zenginleştirmeye odaklanmaktadır (Gretzel vd., 2015: 181). Örneğin hizmet otomasyonu yapay zeka ve robotlarla turizm işletmeleri müşterilerine yeni hizmetler oluşturma fırsatı sağlamaktadır. Müşteriler; müşteri ilişkileri, satın alma kararları, ödeme sistemleri gibi hizmetleri yapay zeka ile gerçekleştirebilmektedir (İbiş, 2019: 403). Ayrıca büyük veri sistemleriyle birlikte turizm işletmeleri bu veriler ile müşteri profilini analiz edebilmektedir (Zsarnoczky, 2017: 89).

Konum temelli akıllı uygulamalar turizm merkezlerinde en önemli uygulamalar olarak görülmektedir. Destinasyonlardaki yapıları, ilgi çekici yerleri ve turistik hizmetleri bir arada sunarak ziyaretçilere kişiselleştirilmiş hizmetler sunulmaktadır (Jinendra vd., 2012: 115). Otel işletmelerinde; odalarda hareket, 1Sı, ses sensörü; restoran ve lobide konum sensörü, konum beacon otel dışında; 1sı, 1şık sensörü yolda; trafik sensörü otelin sosyal ağlarını takip eden ve yöneticilere geri dönüşüm sağlayan sosyal ağ sistemi gibi otellerde nesnelerin interneti uygulama alanlarına örnek olarak belirtilmiştir (Buhalis ve Leung, 2018: 48). Nesnelerin interneti otellerdeki olanakların kullanılabilirliğini turistlerin konumlarını yol trafik koşulları hakkında veri toplamakta bu durum turistlerin memnuniyetini doğrudan etkilemektedir (Jin vd., 2014). Kullanılan akıllı telefonlar turistlerin destinasyonla ilgili bilgilere ulaşımını kolaylaştırmaktadır (Nabben vd., 2016).

Ayrıca otel işletmeleri yöneticileri harcanan zaman ve insan gücünü azaltırken (Buhalis ve Law, 2008), turist talebi ve tedariği hakkında yapay zeka teknolojisiyle daha iyi pazarlama stratejisi ve insan kaynakları yönetimi uygulamaları sağlayabilmektedir (Claveria vd., 2015). Örneğin Hilton ve Marriot otelleri akıllı oda kavramıyla maliyetlerin bir kısmını azaltma finansal sonuçları iyileştirmeyi sağlayarak popülerlik kazanmıştır. Wynn Las Vegas 4,700 odasına yerleştirdiği Amazon Alexa akıllı cihaz ile misafirlerine sesli komut vererek 1şıkları, perdeleri, televizyonu açıp kapama, sıcaklığı ayarlama gibi imkânlar sağlamaktadır (Balakrishnan, 2016). Endüstri 4.0 teknolojileri ile birlikte yapay zeka ile birleşen robot teknolojileri turizm alanında bütünleştirilmiş hizmet sunulmasına katkı sağlayacaktır (İbiş, 2019: 403). Bu öncüller dikkate alınarak araştırmanın hipotezi ve modeli oluşturulmuştur.

H1: Konaklama işletmeleri yöneticilerinin eğitim seviyesi endüstri 4.0 farkındalığını etkilemektedir. 


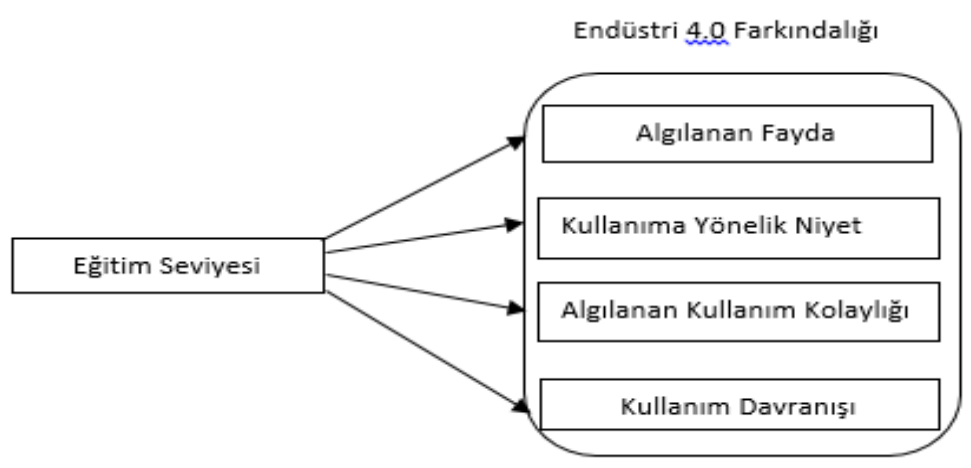

Şekil 1. Araştırma Modeli

Eğitimin teknolojik gelişmeleri uyarıcı etkileri vardır. Bu etkileşim teknolojinin gelişimiyle paralel olarak vasıflı işgücüne olan talebi arttırmaktadır (Demiral, 2019: 197). Endüstri 4.0'ın yeni iş modelleri ortaya çıkarması ve yeni iş ihtiyaçları yüksek eğitim taşıyan nitelikli çalışan ihtiyacını ortaya çıkarmaktadır (Kaygısız ve Sipahi, 2019: 925). Otel işletmelerinin sürdürülebilirliğinin arttırılması, yeniliklere uyum sağlaması ve değişen teknolojiyi yakalamasıyla gerçekleşebilir. Bunun için ise yöneticilerin daha nitelikli eğitime sahip, yenilikleri takip eden ve bu yeniliklere ayak uydurmasını bilen bireylerden oluşması gerekir. Çünkü işletmeler gelecekte üretim süreçlerini gerçekleştirirken iyi bir vizyona sahip ve bu vizyonları yönetebilen eğitimli vasıflı çalışanlara ihtiyaç duyacaktır (Benešová ve Tupa, 2017: 2200-2201).

\section{YÖNTEM}

Araştırmada nicel araştırma yöntemlerinden ilişkisel tarama modeli kullanılmıştır. İlişkisel tarama modeli, iki veya daha çok değişken arasında birlikte değişimin varlığını belirlemeyi amaçlar ve bu yöntemde eğer iki değişken arasında değişme varsa bunun nasıl olduğu saptanmaya çalışlır (Gürbüz ve Şahin, 2014: 105). Bu araştırmanın temel amacl, konaklama işletmelerinde çalışan yöneticilerin eğitim seviyesinin endüstri 4.0 farkındalıklarına etkisini belirlemektir. Araştırmanın ana problemi, "Konaklama yöneticilerinin eğitim seviyesinin endüstri 4.0 farkındalıklarına etkisin var mıdır?" sorusudur.

$\mathrm{Bu}$ araştırmada kullanılan verilerin toplanabilmesi için gerekli olan etik kurul izin belgesi Niğde Ömer Halisdemir Üniversitesi Etik Kurulu 28.01.2021 tarihi ve 02 sayılı toplantısının 08 sayılı kararı ile alınmıştır. Araştırmanın evrenini Nevşehir ilinde faaliyet gösteren konaklama işletmelerinde çalışan yöneticiler oluşturmaktadır. Kapadokya bölgesinde yer alan Nevşehir ili dünya mirası listesinde yer alan ve tanınan bir turizm merkezidir (UNESCO, 2019). Ayrıca, Türkiye turizm gelirleri açısından İstanbul ve Antalya ilinden sonra üçüncü sırada yer almaktadır (TC Kültür ve Turizm Bakanlığı, 2019). Dolayısıyla araştırma verileri 2021 yılının Ocak ve Şubat aylarında, kolayda örnekleme yöntemi ile seçilen ve uygulamaya izin verilen Nevşehir ilindeki konaklama işletmelerinden elde edilmiştir. Nevşehir İl Kültür ve Turizm müdürlüğü verilerine göre, Nevşehir ili sınırları içerisinde 2016 yılı itibariyle, Kültür ve Turizm Bakanlığı'ndan işletme belgeli 62 konaklama işletmesi bulunmaktadır (T.C. Kültür ve Turizm Bakanlığı, 2020). Pandemi sürecindeki kısıtlamalardan dolayı kapalı olan işletmelerden veri toplanamamıştır. Hala faaliyette olan konaklama işletmelerinde çalışan yöneticilerle yüz yüze görüşerek anket formu kullanarak veriler toplanmıştır. 
Araştırmada kullanılan anket formu iki bölümden oluşmaktadır. Birinci bölümde araştırmaya katılan yöneticilerin endüstri 4.0 algılarını ölçmeye yönelik ölçek, ikinci bölümde ise araştırmaya katılanların demografik ve bireysel özelliklerini tespit etmeye yönelik sorular yer almaktadır.

Endüstri 4.0 Farkındalı̆̆ı Ölçeği: Torun ve Cengiz (2019) tarafından geliştirilmiştir. Ölçeğin değerlendirilmesi için 5'li Likert ölçeği kullanılmıştır. Katılımcılara ifadelere ne derece katılıp katılmadıklarına yönelik (1) Kesinlikle Katılmıyorum, (2) Katılmıyorum, (3) Ne Katılıyorum Ne katılmıyorum, (4) Katılıyorum, (5) Kesinlikle Katılıyorum arasında değişen bir puanlama yapmaları istenmiştir. Ölçeğin güvenirliliği $\alpha=.975$ olarak hesaplanmıştır.

Araştırma verileri Ocak ve Şubat 2021 tarihleri arasında yüz yüze görüşme yöntemi ile elde edilmiştir. Araştırmada olasılığa dayalı olmayan örnekleme yöntemlerinden kolayda örnekleme yöntemi kullanılmıştır. Bu yöntemin tercih edilmesinde pandemi sürecinin olması ve kısıtlamalarla birlikte birçok konaklama işletmesinin kapalı olması ve hala faaliyette olan konaklama işletmelerine ulaşmanın zorluğu temel sebeptir. Dolayısıyla araştırmaya katılmayı kabul eden ve hala çalışmakta olan 67 yöneticiye ulaşılmıştır. Fakat araştırmaya eksik bilgi ve özensiz doldurma sebebiyle 63 anket formu dahil edilmiştir. Ayrıca araştırmanın kısıtlarından biride Nevşehir ilindeki tüm konaklama işletmeleri genel müdürleriyle görüşme sağlanamamış bu sebeple araştırmaya departman yöneticileri de dahil edilmiştir. Araştırmada elde edilen veriler, SPSS 22 istatistik paket programı aracıllğıyla analiz edilmiş olup örneklem grubunu oluşturan yöneticilerin demografik ve diğer bireysel özellikleri frekans ve yüzde dağılımları ile sunulmuştur. Araştırmada eğitim seviyesinin endüstri 4.0 farkındalıkları arasındaki ilişki sperman korelasyon testi ile eğitim seviyesinin endüstri 4.0 farkındalıklarına etkisini belirlemek için ise regresyon analizinden yararlanılmıştır.

\section{BULGULAR}

Tablo 1'de araştırmaya katılan yöneticilerin demografik özelliklerine yer verilmiştir:

Tablo 1. Yöneticilerin Demografik ve Diğer Bireysel Özelliklerine İlişkin Bilgiler

\begin{tabular}{|c|c|c|c|}
\hline Değişken & & $\mathbf{F}$ & $\%$ \\
\hline \multirow[t]{2}{*}{ Cinsiyet } & Erkek & 49 & 77,8 \\
\hline & Kadın & 14 & 22,2 \\
\hline \multirow[t]{2}{*}{ Medeni Durum } & Evli & 30 & 47,6 \\
\hline & Bekar & 33 & 55,4 \\
\hline \multirow[t]{3}{*}{ Yaş } & $31-40$ & 9 & 14,3 \\
\hline & $41-50$ & 12 & 19 \\
\hline & 51 ve üzeri & 42 & 66,7 \\
\hline \multirow[t]{3}{*}{ Eğitim } & Lise & 19 & 30,2 \\
\hline & Önlisans & 9 & 14,3 \\
\hline & Lisans & 35 & 55,6 \\
\hline \multirow[t]{4}{*}{ İşletme Tür } & 3 yıldız & 13 & 13,8 \\
\hline & 4 yıldız & 16 & 27,6 \\
\hline & 5 yıldız & 6 & 10,3 \\
\hline & Butik konsept & 28 & 48,3 \\
\hline \multirow[t]{2}{*}{ Sektör Süre } & 6-15 yil & 25 & 39,7 \\
\hline & 15 yıl ve üzeri & 38 & 60,3 \\
\hline
\end{tabular}


Tablo 1'i incelediğimizde araştırma katılımcılarının \%22,2'si kadın, \%77,8'i erkek; \%47,6'sı evli ve \%55,4'ü bekârdır. Katılımcılar yaşları bakımından değerlendirildiğinde, \%14,3'i 31-40 yaş arasında, \%19'u 41-50 yaş arasında \%66,7'si ise 51 ve üzeri yaştadır. Katılımcıların \%30,2'i lise, \%14,3'ü ön lisans, \%55,6'sı lisans mezunudur. Katılımcıların \%13,8'i 3 yıldızlı, 27,6's1 4 yıldızlı,10,3'ü 5 yıldızlı ve 48,3'ü butik konseptte konaklama işletmesinde çalışmaktadır. Ayrıca, katılımcıların \%39,7'si 6-15 yıl arasında, \%60,3'ü ise 16 yıl ve üzerinde turizm sektöründe çalışanlar oluşturmaktadır.

\section{Eğitim Seviyesinin Endüstri 4.0 Farkındalığı Üzerine Etkilerine Yönelik Bulgular}

Araştırmada verilerin normal dağılıma uygunluğunun test edilmesi için yaygın normal dağı̆lıma uygunluk testleri Kolmogorov Smirnov ve Shaphiro Wilk testleri kullanılmıştır. Grup büyüklüğü 50 'den az olması durumunda Shapiro-Wilk, 50'den fazla olması durumunda ise Kolmogorov Smirnov testlerinin kullanılması gerekmektedir. Eğer anlamlılık düzeyi 0,05'den büyük ise dağılımın normal dağılım, küçük çıktıysa dağılımın normal dağılım olmadığı sonucu ortaya çlkmaktadır (Gürbüz ve Şahin, 2014: 236-237). Araştırma büyüklüğü 50' den fazla olduğu için bu araştırmada Kolmogorov Smirnov testi kullanılmış ve verilerin normal dağılım göstermediği tespit edilmiştir $(\mathrm{p}=0,00<0,05)$. Dolayısıyla araştırmada kullanılacak ilişki analizinde parametrik olmayan testler arasında yer alan Spearman Korelasyon testi uygulanmıştır. Konaklama işletmeleri yöneticilerinin eğitim seviyesinin endüstri 4.0 farkındalığı arasındaki ilişkiyi belirlemeye yönelik gerçekleştirilen spearman korelasyon analizi Tablo 2'te sunulmuş̧tur.

Tablo 2. Eğitim Seviyesi ile Endüstri 4.0 Farkındalığı Arasındaki İlişkiye Yönelik Korelasyon Matrisi

\begin{tabular}{|c|c|c|c|c|c|c|c|}
\hline & $X$ & Ss & 1 & 2 & 3 & 4 & 5 \\
\hline $\begin{array}{l}\text { 1.Eğitim } \\
\text { Seviyesi }\end{array}$ & 2,25 & 0,89 & - & & & & \\
\hline $\begin{array}{l}\text { 2. Algilanan } \\
\text { Fayda }\end{array}$ & 3,38 & 1,03 & $0,848^{* *}$ & - & & & \\
\hline $\begin{array}{l}\text { 3.Kullanıma } \\
\text { Yönelik } \\
\text { Niyet }\end{array}$ & 3,64 & 0,82 & $0,845^{* *}$ & $0,948^{* *}$ & - & & \\
\hline $\begin{array}{l}\text { 4.Algılanan } \\
\text { Kullanım } \\
\text { Kolaylığı }\end{array}$ & 3,73 & 0,87 & $0,855^{* *}$ & $0,882^{* *}$ & $0,925^{* *}$ & & \\
\hline $\begin{array}{l}\text { 5. Kullanım } \\
\text { Davranışı }\end{array}$ & 3,93 & 1,09 & $0,863^{* *}$ & 0,820 & 0,809 & 0,847 & - \\
\hline
\end{tabular}

** Korelasyon 0.01 seviyesinde anlamlı (2-uçlu).

Sonuçlar incelendiğinde Endüstri 4.0 farkındalık boyutlarının kendi aralarındaki ilişkilerin tamamında pozitif yönlü anlamlı ilişkiler görülmektedir. Algılanan Fayda ile Kullanıma Yönelik Niyet arasında ( $\mathrm{r}=845)$; Algılanan Fayda ile Algılanan Kullanım Kolaylığı arasında ( $\mathrm{r}=855)$; Algılanan Fayda ile Kullanım Davranışı arasında $(\mathrm{r}=0,863)$, Kullanıma Yönelik Niyet ile Algılanan Kullanım Kolaylığı arasında ( $\mathrm{r}=0,882)$, Kullanıma Yönelik Niyet ile Kullanım Davranışı arasında $(\mathrm{r}=0,820)$ yüksek kuvvette ilişki söz konusudur. Ortaya çıkan bu sonuçlar, Endüstri 4.0 
farkındalık boyutlarındaki artışın, Endüstri 4.0 farkındalığının tüm boyutlarında yüksek kuvvette artış hissettirdiği şeklinde değerlendirilebilir.

Eğitim seviyesi ile endüstri 4.0 farkındalık boyutları arasındaki ilişkiye baktığımızda ise, Eğitim Seviyesi ve Algılanan Fayda ( $\mathrm{r}=0,848)$, Kullanıma Yönelik Niyet $(\mathrm{r}=0,948)$, Algılanan Kullanım Kolaylığı $(\mathrm{r}=0,606)$ ve Kullanım Davranışı $(\mathrm{r}=0,847)$ arasında pozitif yönde yüksek kuvvette bir ilişki vardır. Bu sonuçlar eğitim seviyesindeki herhangi bir artışın, endüstri 4.0 farkındalığına yüksek kuvvette artış hissettirdiği şeklinde değerlendirilebilir.

\section{Eğitim Seviyesinin Endüstri 4.0 Farkındalığına Etkisi}

Bu araştırmada bir değişken üzerinde birden fazla bağımsız değişkenin etkisini incelemek için çoklu regresyon analizi yapılmıştır. Konaklama işletmeleri yöneticilerinin eğitim seviyesinin endüstri 4.0 farkındalığına etkilerini incelemek üzere çoklu regresyon analizi aşağıda yer almaktadır.

Tablo 3. Regresyon Analizi Sonuçları

\begin{tabular}{|c|c|c|c|c|c|}
\hline \multirow[t]{2}{*}{ Değişkenler } & \multicolumn{2}{|c|}{ Standardize edilmemiş } & \multirow{2}{*}{$\begin{array}{l}\text { Standart } \\
\text { Beta }\end{array}$} & \multirow[t]{2}{*}{$\mathbf{T}$} & \multirow[t]{2}{*}{$\mathbf{P}$} \\
\hline & B & S.H. & & & \\
\hline Sabit & 1,049 & 0,159 & & 6,616 & 0,00 \\
\hline Algılanan Fayda & 1,034 & 0,65 & 0,896 & 15,80 & 0,00 \\
\hline $\begin{array}{l}\text { Kullanıma } \\
\text { Yönelik Niyet }\end{array}$ & 0,705 & 0,76 & 0,766 & 9,30 & 0,00 \\
\hline $\begin{array}{l}\text { Algılanan } \\
\text { Kullanım } \\
\text { Kolaylığı }\end{array}$ & 0,851 & 0,61 & 0,874 & 14,0 & 0,00 \\
\hline $\begin{array}{l}\text { Kullanma } \\
\text { Davranışı }\end{array}$ & 1,050 & 0,79 & 0,862 & 13,3 & 0,00 \\
\hline
\end{tabular}

Not: $R 2=0,846 ; F(4,58)=79,748, p<0,001 p<0,05$

Eğitim seviyesinin endüstri 4.0 farkındalığına etkisine ilişkin yapılan çoklu regresyon analizine yönelik bulgular Tablo 3' te verilmiştir. Tabloya göre bağımsız değişken olan eğitim seviyesi bağımlı değişken olan endüstri 4.0 farkındalığına ait varyansın \%84 oranında açıkladığı, bağımlı değişkenin \%84 oranında bağımsız değişkenlere bağlı olarak şekillendiği tespit edilmiştir Çoklu regresyon analizi sonuçları istatistiksel olarak anlamlıdır $(\mathrm{F}=(4,58)=79,748, \mathrm{p}<0,001)$. Bu değerlere göre konaklama işletmeleri yöneticilerinin endüstri 4.0 farkındalıklarının $\% 84$ 'lük varyansının eğitim seviyesine bağlı olduğu görülmektedir. Dolayısıyla konaklama işletmeleri yöneticilerinin eğitim seviyesi endüstri 4.0 farkındalıklarında belirleyici rol oynamaktadır.

Katsayıların yer aldığı tablo ise regresyon denklemi için kullanılan katsayıların anlamlılık değerini (sig) göstermektedir. Buna göre endüstri 4.0 farkındalı̆̆ını açıklamada Algılanan Fayda (Beta $=0,89, \mathrm{p}<0,001$ ), Kullanıma Yönelik Niyet (Beta $=0,76, \mathrm{p}<0,001$ ), Algılanan Kullanım Kolaylığı(Beta $=0,87, \mathrm{p}<0,001$ ) ve Kullanma Davranışı (Beta $=0,86, \mathrm{p}<0,001$ ), anlamlı katkısı vardır. Yöneticiler, çalışma ortamında sürekli rekabet ortamında örgütün karlılığını arttırma için yenilikleri ve değişimleri takip etmek durumundadır. Dolayısıyla bu sonuçlar, eğitimin uyarıcı etkisinin olmasından dolayı yöneticilerin eğitim seviyesindeki artışın endüstri 4.0 farkındalıklarını etkilediğini göstermektedir. 


\section{SONUÇ, TARTIŞMA ve ÖNERİLER}

Nevşehir ilinde bulunan konaklama işletmelerinde yönetici pozisyonunda çalışan işgörenlerin eğitim seviyesinin endüstri 4.0 farkındalıklarına etkisinin belirlenmesini amaçlayan bu çalışmada 63 yöneticiye anket uygulanmıştır. Araştırmaya katılan yöneticilerin çoğunluğu; erkek, lisans mezunu ve 51 yaş ve üzeri aralığında yaşa sahiptir.

Araştırmada eğitim seviyesinin endüstri 4.0 farkındalığına etkisini araştırmak için korelasyon ve regresyon analizi yapılmıştır. Korelasyon analizi sonucunda yöneticilerin eğitim seviyeleri ile endüstri 4.0 farkındalığı arasında pozitif yönde yüksek oranda ilişkiler tespit edilmiştir. Bu sonuçlar; yöneticilerin eğitim seviyesinin endüstri 4.0 farkındalığına orantılı olduğunu ve eğitim seviyeleri ile endüstri 4.0 farkındalıkları paralel yönde artış ya da azalış gösterdiğini belirtmektedir.

Nevşehir ilinde gerçekleştirilen bu araştırmada konaklama işletmeleri yöneticilerinin eğitim seviyesinin endüstri 4.0 farkındalığ üzerinde etkili olduğu sonucuna ulaşılmıştır. Araştırmada bu etkinin belirlenmesine yönelik gerçekleştirilen regresyon analizi sonuçlarına göre "H1: Konaklama işletmeleri yöneticilerinin eğitim seviyesi endüstri 4.0 farkındalığını etkilemektedir." hipotezi kabul edilmiştir. Ebso (2015)'e göre endüstri 4.0 teknolojileri yüksek kalifiye iş gücüne yönelik istihdamda artış olacağını öngörmektedir. İşletmelerin önümüzdeki süreçlerde bir vizyona sahip olmaları önemlidir ve bu vizyonları yönetebilmeleri için vasıflı iyi eğitimli bireylere ihtiyaç duyulacaktır (Benešová ve Tupa, 2017: 2200-2201). Ayrıca eğitimin teknolojik gelişmeleri uyarıcı etkileri vardır (Demiral, 2019: 197). Dolayısıyla yöneticilerin eğitim seviyesi konaklama işletmelerinin bu yeniliklere ne kadar hazırlıklı olduğunun bir göstergesi olduğu düşünülmektedir.

\section{Araştırmanın Teorik Katkıları}

Literatürde otel işletmeleri yöneticilerinin eğitim seviyesi ile endüstri 4.0 farkındalıkları arasındaki ilişkiye yönelik ampirik bir çalışmaya rastlanmamıştır. Dolayısıyla çalışma, otel işletmeleri yöneticilerinin eğitim seviyesinin endüstri 4.0 farkındalıkları üzerindeki etkisinin değerlendirilmesi açısından önem teşkil etmekte ve çalışma ile ilgili literatüre katkı sağlaması öngörülmektedir. Araştırmada korelasyon ve regresyon analizi sonucunda ortaya koyulan sonuçlar otel işletmeleri yöneticilerinin eğitim seviyesinin endüstri 4.0 farkındalıkları üzerinde pozitif ve anlamlı etkiye sahip olduğu tespit edilmiştir. Bu doğrultuda otel işletmeleri yöneticilerinin eğitim seviyesi arttıkça veya azaldıkça endüstri 4.0 farkındalıkları da o yönde artmakta veya azalmaktadır. Literatürde sınırlı sayıda yapılan araştırmalar (Prokopowicz, 2018, Clavert, 2019; Gueye ve Exposito, 2020) eğitim seviyesi ile endüstri 4.0 farkındalıkları arasında doğru orantılı bir ilişki olduğunu göstermektedir. Dolayısıyla araştırma sonuçları; otel işletmeleri yöneticilerinin eğitim seviyeleri ile endüstri 4.0 algıları arasındaki ilişki açısından literatürde var olan temel düşünceyi destekler niteliktedir.

\section{Araştırmanın Pratik Katkıları ve Öneriler}

Nevşehir ilindeki konaklama işletmelerinde yöneticilerin birçoğu aynı zamanda konaklama işletmesinin sahibidir. Herhangi bir mülakat veya eleme yoluyla seçilmeyen bu yöneticilerin nitelikleri konusunda eksiklikleri olduğu düşünülmektedir. Bu araştırmanın değişen dünya düzenine göre uyum sağlamak zorunda olan konaklama işletmelerinin eksikliklerinin farkında olmasını sağlayacağı düşünülmektedir. Yöneticilerin yeni teknolojilere uyum sağlaması için bu konuda uzman kuruluşlardan yardım alınabilir. Konaklama işletmelerinde misafirlerin kendilerini evlerinde hissetmeleri için yeni düzenlemeler getirilebilir. Örneğin misafir otele gelmeden oda ısısını ayarlayabilir, aynı konaklama tesisinde kalırken diğer aile bireylerinin konaklama tesisinin hangi konumunda olduğunu bilebilir, sevdiği müzik odasına gelmeden 
odasında çalmaya başlayabilir. Bu öneriler tamamen kişisel ihtiyaçları ne kadar "özel hale getirebiliriz" in cevabıdır. Konaklama işletmeleri yöneticileri; "Tatile gittiklerinde bir konaklama işletmesinde kendisini özel hissettirecek ne olabilir?" sorusuna cevap aradıklarında bu teknolojilerin uygulama biçimi arayışına girecekleri düşünülmektedir. Ayrıca yöneticilerin ve uygulayıcıların çağa uyum sağlaması, bu yönde yeni stratejiler belirlemesi, yeni pazarlama yöntemleri uygulamaları açısından da araştırmanın sektöre çalışanlarına katkı sağlayacağı düşünülmektedir.

$\mathrm{Bu}$ araştırma Nevşehir ilindeki konaklama işletmeleri yöneticilerine uygulanmıştır. Fakat araştırmanın evreni içerisinde yer alan konaklama işletmeleri yöneticilerinin tamamına ulaşılamamıştır. Pandemi sürecindeki kısıtlamalardan dolayı kapalı olan konaklama işletmelerinden veri toplanamamıştır. Dolayısıyla araştırma kısıtlarından biri evrenin tamamına ulaşamamaktır. Ayrıca literatürde, konaklama işletmeleri yöneticilerinin eğitim seviyesinin endüstri 4.0 farkındalıklarına etkisini inceleyen araştırmaya rastlanmamıştır. Araştırmanın kısıtlarından biride araştırma sonuçlarını karşılaştırma ve değerlendirme imkanının olmamasıdır. Elde edilen sonuçlar daha sonra yapılacak olan çalışmalara temel olabilir, farklı değişkenler kullanarak veya farklı örneklemlerle çalışılarak farklı sonuçlar elde edilebilir.

\section{KAYNAKÇA}

Andreas, S., Selim, E. and Sihn, W. (2016). A Maturity Model for Assessing Industry 4.0 Readiness and Maturity of Manufacturing Enterprises, Procedia CIRP, 52: 161-166.

Balakrishnan, B. and Woods, P. C. (2007). Virtual Laboratories in Engineering Education: The Simulation Lab and Remote Lab, Computer Applications in Engineering Education, 17: 108-118.

Benešová, A. and Tupa, J. (2017). Requirements for Education and Qualification of People in Industry 4.0. Procedia Manufacturing, 11: 2195-2202.

Buhalis, D. and Law, R. (2008). Progress in Information Technology and Tourism Management: 20 Years on and 10 Years After the Internet - The State of eTourism Research. Tourism Management, 29(4): 609-623.

Buhalis, D. and Leung, R. (2018). Smart Hospitality Interconnectivity and Interoperability Towards an Ecosystem, International Journal of Hospitality Management, 71: 41-50.

Bulut, E. ve Akçacı, T. (2017). Endüstri 4.0 ve İovasyon Göstergeleri Kapsamında Türkiye Analizi, ASSAM Uluslararası Hakemli Dergi, 4(7): 55-77.

Claveria, O., Monte, E. and Torra, S. (2015). A New Forecasting Approach for the Hospitality Industry, International Journal of Contemporary Hospitality Management, 27(7): 1520-1538.

Clavert, (2019). Industry 4.0 Implications for Higher Education Institutions. [Online] https://universitiesofthefuture.eu/wp-content/uploads/2019/02/State-of-Maturity_Report.pdf [Erişim Tarihi: 20.03.2021].

Demiral, G. (2019). Endüstri 4.0 ‘n İnsan Kaynaklarına Yönelik Etkileri: Teknolojik Değişim Farkındalığı Üzerine Bir Araştırma, Ekev Akademi Dergisi, 23(80): 191-208.

Dengiz O. (2017). Endüstri 4.0: Üretimde Kavram ve Alg1 Devrimi, Makina Tasarım ve İmalat Dergisi, 15(1): 38-45.

Dominquez, C.D., Hernandez, R.M., Talavera, A.S. and Lpez, E.P. (2015). Strategic Determinants in the Theoretical Framework of the Smart Islands: The Case of the Island of El Hierro. Forum Global Conference: Tourism Intelligence in Action, (p. 1-28). Naples, Italy. 
Ebso, (2015). Sanayi 4.0, [Online] Ege Bölgesi Sanayiciler Odası, Araştırma Müdürlüğü, http://www.ebso.org.tr/ebsomedia/documents/sanayi-40_88510761.pdf [Erişim Tarihi: 20.01.2021].

Firat, O ve Fırat, S. (2017). Endüstri 4.0 Yolculuğunda Trendler ve Robotlar, İstanbul Üniversitesi İşletme Fakültesi Dergisi, 46(2): 211-223.

Gretzel, U. (2010). Travel in the Network: Redirected Gazes, Ubiquitous Connections and New Frontiers. In M. Levina \& G. Kien (Eds.), Post-global Network and Everyday Life, New York: Peter Lang

Gueye, M. and Exposito, E. (2020). University 4.0: The Industry 4.0 Paradigm Applied to Education. IX Congreso Nacional de Tecnologías en la Educación, October, Puebla (Mexico), France.

Gürbüz, S. ve Şahin, F. (2014). Sosyal Bilimlerde Araştırma Yöntemleri, Felsefe-Yöntem Analiz, İkinci Baskı, Ankara, Seçkin Yayıncılık.

İbiş, S. (2019). Robotization in the tourism industry. Journal of Turkish Tourism Research, 3(3), 403420 .

Jin, J., Gubbi, J., Marusic, S. and Palaniswami, M. (2014). An Information Framework for Creating a Smart City through Internet of Things, IEEE Internet Things Journal, 1(2): 112-121.

Jinendra, R. D., Bhagyashri, R. J., Pranav, G. Y., Seema, V. U. and Parag, N. A. (2012). Smart Travel Guide: Application for Android Mobile, International Journal of Electronics, Communication \& Soft Computing Science \& Engineering, (Special Issue): 115-120.

Karamustafa, K. ve Yılmaz, M. (2019). Konaklama İşletmeleri Yöneticilerinin Akıllı Turizm Teknolojilerinin Olası Faydalarına Yönelik Algılarının Değerlendirilmesi, Journal of Tourism and Gastronomy Studies, 7(3): 1669-1688. DOI: 10.21325/jotags.2019.442.

Kaygısız E. ve Sipahi H. (2019). Y Kuşağı Üniversite Öğrencilerinin Bireysel Yenilik ve Endüstri 4.0 Bilgi Düzeyleri Arasındaki İlişkinin İncelenmesi, Gaziantep Üniversitesi Sosyal Bilimler Dergisi 18(2): 922-936.

Mrugalska, B. and Wyrwicka, M. K. (2017). Towards Lean Production in Industry 4.0. 7th International Conference on Engineering, Project, and Production Management - Procedia Engineering, 182: 466-473.

Nabben, A., Wetzel, E., Oldani, E., Huyeng, J., Boel, M. and Fan, Z. (2016). Smart Technologies in Tourism: Case Study on the Influence of Beacons on Customer Experience during the 2015 SAIL Amsterdam Event, In the International Tourism Student Conference, Madrid, Spain.

Özdemir Akgül, S. (2019). Turizm 4.0 ve Yapay Zeka Uygulamaları. İçinde Turizm 4.0 Dijital Dönüşüm, Sezgin, M., Özdemir Akgül, S., Atar, A. (Editör). Detay Yayıncılık. Ankara.

Prokopowicz, D. (2018). How Can You Describe the Correlation Between the Industry 4.0 Technological Revolution and Modern 4.0 Education? Cardinal Stefan Wyszynski University in Warsaw, [Online] https://www.researchgate.net/post/The-Learning-Factory-for-Industry-40 [Erişim Tarihi: 20.03.2021].

Rennung, F., Luminosu C. T. and Draghici, A. (2016). Service Provision in The Framework of Industry 4.0. Procedia Social and Behavioral Sciences, 221:372-377.

Rojko, A. (2017). Industry 4.0 Concept: Background and Overview, International Journal of Interactive Mobile Technologies, 11(5): 77-90. 
Soylu, A. (2018). Endüstri 4.0 ve Girişimcilikte Yeni Yaklaşımlar, Pamukkale Üniversitesi Sosyal Bilimler Enstitüsü Dergisi, 32: 43-5. DOI: 10.30794/pausbed.424955.

T.C. Kültür ve Turizm Bakanlığı, (2020) Turizm Tesisleri, [Online] https://yigm.ktb.gov.tr/TR9579/turizm-tesisleri [Erişim Tarihi: 20.12.2020].

Thames L. and Schaefer, D. (2016). Software Defined Cloud Manufacturing for Industry 4.0. Procedia CIRP, 52: 12-17.

Topsakal, Y., Yüzbaşığlu, N. ve Çuhadar, M. (2018). Endüstri Devrimleri ve Turizm: Türkiye Turizm 4.0 SWOT Analizi ve Geçiş Süreci Önerileri, Süleyman Demirel Üniversitesi İ̈BF Dergisi, 23, Endüstri 4.0 ve Örgütsel Değişim Özel Sayısı, 1623-1638.

Torun, N ve Cengiz, E. (2019). Endüstri 4.0 Bakış Açısının Öğrenciler Gözünden Teknoloji Kabul Modeli (Tkm) ile Ölçümü, Uluslararası İktisadi ve İdari Íncelemeler Dergisi, 22: 235-250. DOI: 10.18092/ulikidince.444410

Unesco, (2019). [Online] https //www.unesco.org.tr/Pages/125/122/UNESCO-D\%C3\%BCnyaMiras\%C4\%B1- List [Erişim Tarihi: 20.01.2021].

Yang, L.U. (2017). Industry 4.0: A Survey on Technologies, Applications and Open Research Issues, Journal of Industrial Information Integration, 6: 1-10.

Yelkikalkan N., Özcan S. ve Temel K. (2019). Endüstri 4.0 Farkındalığının Belirlenmesi: Çanakkale Onsekiz Mart Üniversitesi Örneği, Journal of Entrepreneurship and Development, 14(1): 31-44.

Zsarnoczky, M. How does artificial intelligence affect the tourism industry? Vadyba Journal of Journal of Management, 2(31): 1648-7974. 